\title{
Extreme response bias and associative commonality
}

An explanation of extreme responses in the semantic differential in terms of the availability of intense responses which are not inhibited, was tested by relating frequency of extreme responses to associative commonality in word association. A small but significant relationship was found amongst teachers' training college students.

The tendency of some Ss to check extreme positions in rating scales has been noted by many investigators. Most of the investigations were done within the framework of personality theory. Thus Brengelmann (1960) related rigidity of personality to the tendency to give extreme responses; Lewis \& Taylor (1955) related anxiety; Mogar (1960) authoritarianism; and Arthur (1966) found extreme responses on the semantic differential to be more characteristic of neurotics and psychotics than of normals.

This study was carried out as an attempt to seek out cognitive variables which produce extreme responses, since cognitive variables are more fundamental than personality variables and must underlie any personality differences. A cognitive explanation was therefore formulated: that normal Ss who respond with extreme responses on the semantic differential do so because of a greater availability of (a) intense responses which they (b) do not inhibit. One test of this explanation is the expectation that in a word association task these same Ss will give responses which are more common in the population. This is expected because there is evidence that responses common in the population are more intense and more available in individuals: i.e., they are more probable and have shorter latencies (Osgood, Suci, \& Tannenbaum, 1957). Thus the hypothesis was tested that a S's tendency to give extreme responses in the semantic differential is related to his tendency to give words with greater associative commonality in word association.

\section{Method}

Subjects. Forty teachers' training college students, 22 females and 18 males, whose age range was 17 to 20 years.

Tests. (1) A standard form of the semantic differential was used consisting of 10 scales: kind-cruel, passiveactive, good-bad, weak-strong, true-false, fast-slow, hard-soft, ugly-beautiful, wise-foolish, and masculinefeminine. Ten concepts were rated on each of the scales: BOULDER, MY MOTHER, SYMPHONY, MYSELF, CONSCIENCE, CHOCOLATE, SIN, FRIEND, QUEEN, and OCEAN. A standard set of instructions was used. Response bias was measured in terms of the frequency of extreme categories of response, 1 and 7 , in each $\mathrm{S}$.

(2) A written list of 20 stimulus words from KentRosanoff: DEEP, BUTTERFLY, SMOOTH, COLD, WISH, RIVER, BEAUTIFUL, RED, FOOT, SLEEP, EARTH, WINDOW, CABBAGE, BIBLE, BATH, COTTAGE, GREEN, THIRSTY, BABY, and STREET. Brief instructions to write down the first word that each made one think of, were given, including advice to work rapidly. Associative commonality was measured in terms of the frequency of response words for the group of $40 \mathrm{Ss}$. For example, if a response word was used eight times in connection with any particular word, it was assigned a score of 8 . If a response word appeared only once, it was given a score of 1 . The associative commonality score for each $\mathrm{S}$ was the sum of these assigned scores, less 20 , which was a minimum for each $S$, if he responded uniquely.

\section{Resulis}

The mean and standard deviation for the frequency of extreme responses were 28.5 (SD, 16.6) and for associative commonality 37.8 (SD, 13.4). The productmoment correlation coefficient between extreme responses and associative commonality proved to be $+.34(\mathrm{p}<.05)$.

\section{Discussion}

The results confirmed the hypothesis that extreme responses are related to associative commonality and that therefore they may be partially mediated by a mechanism of greater availability of intense responses which are not inhibited. Although the relationship $r=.34$ is small, it has a great theoretical significance. In addition, it establishes a relationship between two dissimilar measures, semantic differential and word association, where previous studies tended to relate similar measures: rating scales and questionnaires.

\section{References}

Arthur, A. Z. Response bias in the semantic differential. Brit. $J$. soc. clin. Psychol., 1966, 5, 103-107.

Brengelmann, J. C. A note on questionnaire rigidity and extreme response set. J. ment. Sci., 1960, 106, 187-192.

Lewis, N. A., \& Taylor, J. A. Anxiety and extreme response preferences. Educ. psychol. Measmt., 1955, 15, 111-116.

Mogar, R. E. Three versions of the F scale and performance on the semantic differential. J. abnorm. soc. Psychol., 1960, 60, 262265.

Osgood, C. E., Suci, G. J., \& Tannenbaum, P. H. The measurement of meaning. Urbana: University of Illinois Press, 1957. 